\title{
Nutritional value of vegetable Amaranthus tricolor L. seedlings grown in Moscow region
}

\author{
Iskren G. Sergiev*1, Desislava A. Todorova ${ }^{1}$, Valentina K. Gins ${ }^{2}$, \\ Svetlana M. Motyleva ${ }^{3}$, Ekaterina M. Gins ${ }^{4}$, Evgeny A. Moskalev ${ }^{4}$ \\ ${ }^{1}$ Institute of Plant Physiology and Genetics, Bulgarian Academy of Sciences, Sofia, Bulgaria \\ ${ }^{2}$ Federal Scientific Vegetable Center, VNIISSOK village, Russian Federation \\ ${ }^{3}$ All-Russian Horticultural Institute for Breeding, Agrotechnology and Nursery, \\ Moscow, Russian Federation \\ ${ }^{4}$ Lorch Potato Research Institute, \\ Kraskovo village, Moscow Region, Russian Federation \\ *Corresponding author: iskren@bio21.bas.bg
}

\begin{abstract}
The use of amperometric express method made it possible to measure quickly and evaluate content of water- and alcohol-soluble antioxidants in extracts from Amaranthus tricolor L. plants. Accumulation of low molecular weight antioxidants: ascorbic acid, beta-cyanine (amaranthine) and the total content of antioxidants in various organs of Valentina amaranth seedlings were studied. The maximum amount of low molecular weight antioxidants accumulates in leaves, compared with roots and stems of seedlings grown in open and protected ground. In open ground conditions, amaranth leaves and stems have 1.5-fold and 2-fold increased level of ascorbic acid than seedlings grown in protected ground. But the total content of water-soluble antioxidants in leaves and roots of seedlings is lower compared to seedlings of protected ground. Minimum amount of antioxidants was found in alcohol extracts of stems and roots in open ground, while the total content of antioxidants in stems and roots was 1.6 fold higher in seedlings grown in protected soil. The content of amaranthine is comparable in the studied organs of amaranth seedlings of both cultivation variants. The data obtained allow to recommend use of leaves and stems of amaranth seedlings grown in open and protected ground (early spring and autumn), as a preventive antioxidant dietary product.
\end{abstract}

Key words: Amaranthus tricolor L. seedlings, water and alcohol extracts, low molecular weight antioxidants, amaranthine, ascorbic acid, open ground, protected ground

\section{Article history:}

Received: 16 August 2019. Accepted: 30 August 2019

\section{For citation:}

Sergiev IG, Todorova DA, Gins VK, Motyleva SM, Gins EM, Moskalev EA. Nutritional value of vegetable Amaranthus tricolor L. seedlings grown in Moscow region. RUDN Journal of Agronomy and Animal Industries, 2019; 14(3):225-238. doi: 10.22363/2312-797X-2019-14-3-225-238

(C) Сергиев И.Г., Тодорова Д.А., Гинс В.К., Мотылева С.М., Гинс Е.М., Москалев Е.А., 2019.

(c) (i) This work is licensed under a Creative Commons Attribution 4.0 International License https://creativecommons.org/licenses/by/4.0/1 


\title{
Пищевая ценность сеянцев овощного вида Amaranthus tricolor L., \\ выращенных на зелень рассадным способом в условиях Московской области
}

\author{
И.Г. Сергиев ${ }^{1}$, Д.А. Тодорова ${ }^{1}$, В.К. Гинс르, С.М. Мотылева ${ }^{3}$, \\ Е.М. Гинс ${ }^{4}$, Е.А. Москалев ${ }^{4}$
}

${ }^{1}$ Институт физиологии и генетики Болгарской академии наук, София, Болгария

${ }^{2}$ Федеральный научный центр овощеводства,

n. ВНИИССОК, Московская область, Российская Федерация

${ }^{3}$ Всероссийский селекционно-технологический институт садоводства и питомниководства, Москва, Российская Федераџия

${ }^{4}$ Всероссийский научно-исследовательский институт картофельного хозяйства имени А.Г. Лорха,

n. Красково, Московская область, Российская Федераџия

*Автор-корреспондент: iskren@bio21.bas.bg

\begin{abstract}
Аннотация. Использование амперометрического экспресс-метода позволило оперативно измерить и оценить содержание водо- и спирторастворимых антиоксидантов в экстрактах из растений Amaranthus tricolor L. Исследовали накопление низкомолекулярных антиоксидантов: аскорбиновой кислоты, бетацианина - амарантина и суммарное содержание антиоксидантов в различных органах сеянцев амаранта сорта Валентина. Максимальное количество низкомолекулярных антиоксидантов накапливается в листьях, по сравнению с корнями и стеблями сеянцев, выращенных в открытом и защищенном грунте. В условиях открытого грунта уровень аскорбиновой кислоты в листьях в 1,5 и в стеблях амаранта в 2 раза выше, чем в сеянцах в защищенном грунте. В то время как суммарное содержание водорастворимых антиоксидантов в листьях и корнях сеянцев меньше по сравнению с сеянцами защищенного грунта. В спиртовых экстрактах стеблей и корней обнаружено минимальное количество антиоксидантов в открытом грунте, при этом суммарное содержание антиоксидантов в стеблях и корнях в 1,6 раза выше у сеянцев защищенного грунта. Содержание амарантина сравнимо в исследованных органах сеянцев амаранта обоих вариантов выращивания. Полученные данные позволяют рекомендовать использование листьев и стеблей сеянцев амаранта, выращенных в открытом и защищенном грунте (ранней весной и осенью), в качестве профилактического антиоксидантного продукта диетического назначения.
\end{abstract}

Ключевые слова: сеянцы Amaranthus tricolor L., водные и спиртовые экстракты, низкомолекулярные антиоксиданты, амарантин, аскорбиновая кислота, открытый грунт, защищенный грунт

\section{История статьи}

Поступила в редакцию: 16 августа 2019 г. Принята к публикации: 30 августа 2019 г.

\section{Для цитирования}

Сергиев И.Г., Тодорова Д.А., Гинс В.К., Мотылева С.М., Гинс Е.М., Москалев Е.А. Пищевая ценность сеянцев овощного вида Amaranthus Tricolor L., выращенных на зелень рассадным способом в условиях Московской области // Вестник Российского университета дружбы народов. Серия: Агрономия и животноводство. 2019. Т. 14. № 3. С. 225-238. doi: 10.22363/2312-797Х-2019-14-3-225-238

\section{Introduction}

In hot and humid regions of the world, edible species of leafy amaranths (genus Amaranthus) are considered to be popular vegetable crops: A. tricolor, A. blitum, A. dubius, A. cruentus and A. Viridis [1-3]. In many countries of Africa and Southeast 
Asia, India, southern China, amaranth leafy greens are widely used for food purposes, growing it as parsley, leaves and stems of which are used for food purposes. Young plants of vegetable species of amaranth are used in a variety of salads, appetizers, side dishes, soups, fillings for confectionery, drinks, pasta and even traditional medicine [4-7].

Such widespread use of vegetable amaranth as a food product is explained by a number of reasons, including the fact that spicy aromatic plants are practically not grown in these countries, and amaranth makes up for greens in many dishes $[8,9]$. The popularity of amaranth vegetables is due to their mild piquant taste and high nutritional value, leaves of which are rich in gluten-free protein, vitamins, minerals, especially calcium, iron, as well as biologically active substances [10]. In addition, in a number of countries there is a shortage of animal protein, and leaves of amaranth vegetable species contain up to $20 \%$ of a complete protein, balanced for essential amino acids. Therefore, population of these regions replenishes the lack of dietary protein by leaves of wild vegetable amaranth, growing seedlings and preparing various diets based on them [11].

Amaranth seedlings (young plants) are a commercial product in some countries. In Indonesia, amaranth vegetables are grown on an area of 2000 hectares. In tropical countries, amaranth is sown year-round. Due to the short development cycle of seedlings (7-8 weeks), they are cut for food several times a year.

Cultivation of vegetable amaranth in non-chernozem zone faces a number of problems. For example, return cold in spring months of April-May does not allow sowing of amaranth seeds in open ground before the end of May or the beginning of June; moisture deficiency in dry years can ruin the crop, since amaranth seedlings require more watering, compared to adult plants. In addition, amaranth seedlings in open ground can suffer from weeds, whose growth rate is much higher than growth of amaranth seedlings, and later snails can harm young seedlings [12]. When growing amaranth seedlings in a protected ground, such problems do not occur. Therefore, it is important to represent change patterns in the main morphological and biochemical parameters that determine productivity and nutritional and pharmacopoeial value of seedlings grown in open and protected ground.

The aim of the work was to study morphological and biochemical parameters of amaranth seedlings when growing them in open and protected ground for food use.

\section{Materials and methods}

The object of the study are vegetable amaranth plants (Amaranthus tricolor L.) of Valentina cultivar originated in Russian Research Institute of Selection and Seed Production of Vegetable Crops (Moscow Region). Cassettes with pre-moistened peat mixture were used for sowing seeds. Sowing depth was $0.5 \ldots 1 \mathrm{~cm}$. After 4 weeks, the seedlings were transplanted into soil in protected and open ground [13]. Plants were grown on sod-podzolic soil with a heavy mechanical composition at night temperature of $8 \ldots 14^{\circ} \mathrm{C}$ and day temperature $9 \ldots 25^{\circ} \mathrm{C}$ in open ground, and at night temperature $14 \ldots 17^{\circ} \mathrm{C}$ and day temperature $22 \ldots 30^{\circ} \mathrm{C}$ in protected ground.

Young plants aged 6-7 weeks were cut off and morphometric indicators were studied: plant height, mass of plants, leaves, stem, root, length and width of leaf blades. In the experiment, amaranth plants of Valentina cultivar grown in protected and open ground were compared. From each experimental plot, 15 plants were collected. 
Biochemical studies were carried out in the Laboratory of physiology and biochemistry of introduction and functional products of Federal Scientific Technological Center in 2018. Aqueous and alcoholic extracts of leaves, stems and roots of seedlings were used in the experiments.

Extraction of crushed leaves and other plant organs was carried out with distilled water at room temperature (water ratio 1:10), followed by centrifugation at 10,000 rpm. Amount of amaranthine in aqueous extracts was determined spectrophotometrically considering a molar extinction coefficient of $5.66 \cdot 10^{4} \cdot \mathrm{M}^{-1} \cdot \mathrm{cm}^{-1}$ and a molar weight of 726.6 [14]. Content of reduced form of ascorbic acid (AA) was determined by iodometric method based on titration of ascorbic acid in colored extracts with potassium iodate in acidic medium in presence of potassium iodide and starch [15]. The total content of antioxidants was determined by amperometric method, the result was expressed in gallic acid equivalents $\mathrm{mEq} . \mathrm{GK} / \mathrm{g}$. The measurements were performed on a TsvetYauza 01-AA device in a constant current mode [16]. The samples were crushed on a homogenizer in presence of a certain volume of extracting liquid (double-distilled water, $96 \%$ ethanol) at $20 \ldots 25^{\circ} \mathrm{C}$. Then, the homogenizer was centrifuged at $10,000 \mathrm{~g}$ for 15 minutes at $4{ }^{\circ} \mathrm{C}$. An aliquot of the supernatant was used to determine the total antioxidant content, if necessary diluting.

The tables $1-4$ show the arithmetic mean values and standard deviations.

\section{Results and discussions}

Dark-colored A. tricolor seeds of Valentina cultivar germinated with an interval of two days. A slower increase in seedling height was observed in the stage of the first pair of true leaves and a sharp increase in plant height with development of subsequent leaves. Seedlings having well-developed cotyledons and first pair of true leaves were transplanted into protected and open ground.

Analysis of morphometric parameters of plant before cutting revealed that amaranth seedlings grown in sheltered soil had significantly higher morphometric indicators compared to seedlings grown in open ground.

The photosynthetic productivity of aerial parts of plants was significantly higher in seedlings in protected soil. When growing amaranth plants in protected ground at seedling stage, a more massive main shoot (stem) with a smaller mass of leaves is formed compared to open ground plants. Study of structure of seedlings' crop showed that aerial mass of seedlings grown in open ground have $52 \%$ of leaves, $35 \%$ of stems, while young plants in protected ground form $42 \%$ of leaves and $44 \%$ of stems.

Table 1

Determination of structure of Valentina seedlings grown in open and protected ground

\begin{tabular}{|c|c|c|c|c|}
\hline Ground & $\begin{array}{l}\text { Plant } \\
\text { mass, } \\
\text { g }\end{array}$ & $\frac{\text { Leaf mass, } \mathrm{g}}{\text { Percentage by Plant mass, } \%}$ & $\begin{array}{c}\text { Stem mass, } \mathrm{g} \\
\begin{array}{c}\text { Percentage } \\
\text { by Plant mass }\end{array}\end{array}$ & $\begin{array}{c}\text { Root mass, } \mathrm{g} \\
\text { Percentage } \\
\text { by Plant mass }\end{array}$ \\
\hline \multirow{2}{*}{ Open } & \multirow{2}{*}{2.52} & 1.30 & 0.90 & 0.35 \\
\hline & & $52 \%$ & $35 \%$ & $13 \%$ \\
\hline \multirow{2}{*}{ Protected } & \multirow{2}{*}{7.90} & 3.36 & 3.5 & 1.1 \\
\hline & & $42 \%$ & $44 \%$ & $14 \%$ \\
\hline
\end{tabular}


It is interesting to note that root mass of seedlings of both variants was $13 \ldots 14 \%$ of the aboveground mass. This suggests that photosynthetic metabolites in plants of open ground are accumulated in large quantities in leaves, while they are distributed almost evenly between leaves and stems in plants of protected ground.

Gluten-free protein, balanced for essential amino acids, and biologically active substances with antioxidant activity that affect physiological functions of the human body, effectively participating in metabolic and protective reactions comprise nutritional and pharmacopoeial value of Valentina leaves (amaranth A. tricolor L.) [17]. Ascorbic acid is a necessary component for human life. Some vegetable crops accumulate ascorbic acid in high concentrations: bell pepper - up to $200 \mathrm{mg} \%$, leafy vegetable plants: vegetable chrysanthemum - up to $80 \mathrm{mg} \%$, watercress and coriander - up to $150 \mathrm{mg} \%$ [18].

Table 2

Ascorbic acid in Valentina amaranth plant organs

\begin{tabular}{c|c|c}
\hline \multirow{2}{*}{ Plant organs } & \multicolumn{2}{|c}{ Ascorbic acid content, mg\% } \\
\cline { 2 - 3 } & Protected ground & Open ground \\
\hline Leaves & 108 & 167 \\
\hline Stems & 19.8 & 44 \\
\hline Roots & 25.12 & 22.8
\end{tabular}

Amaranth seedlings accumulate reduced ascorbic acid in all organs, but in different amounts. The data presented in table 2 indicate that the maximum amount of ascorbic acid accumulates in leaves of both variants, and the minimum - in stems of seedlings of protected soil and in roots of seedlings of open ground. The data obtained indicate that content of ascorbic acid in various plant organs depends on temperature conditions during cultivation. It is known that plant cell reactive oxygen species are formed at low temperature, where superoxide anion radical is the most dangerous. Ascorbic acid is able to neutralize $\mathrm{O}_{2-}$. In open ground, a decrease in night temperature to $8{ }^{\circ} \mathrm{C}$ and lower for heat-loving seedlings is a stress factor that slows down their growth and development. Therefore, under these conditions, ascorbic acid, whose level in leaves of amaranth grown in open ground, was 1.5 fold higher than that in leaves of plants of protected ground, serves as protection from action of superoxide anion radicals. Compared to leaves, 5.45-fold decreased ascorbic acid was accumulated in stems of protected seedlings and 3.7-fold less accumulated ascorbic acid was in stems of open ground seedlings. An unequal amount of ascorbic acid was found in roots of young plants grown in open and protected ground. Ascorbic acid was accumulated in large quantities in leaves and stems of seedlings grown in open ground, which might indicate its active generation under conditions of weak low-temperature stress. In addition to ascorbic acid, red-colored pigment amaranthine with antioxidant activity comparable to that of superoxide dismutase is involved in the detoxification of the superoxide anion radical [19]. Leaves and inflorescences of amaranth seedlings of both cultivation variants contained practically comparable amounts of amaranthine, while stems of young open-ground plants accumulated 1.5 times more antioxidant than stems of seedlings of protected soil.

Table 3

Amaranthine level in organs of Valentina amaranth plants, mg per g wet weight

\begin{tabular}{c|c|c}
\hline Sample & Protected ground & Open ground \\
\hline Leaves & $0.62 \pm 0.03$ & $0.59 \pm 0.03$ \\
\hline Stems & $0.22 \pm 0.01$ & $0.34 \pm 0.02$
\end{tabular}


The study of the total content of antioxidants in leaves and stems of amaranth seedlings grown in protected and open ground revealed the maximum content of antioxidants in water extracts, which was $2.5-3$ fold higher than the level of antioxidants extracted in alcohol extract.

Table 4

Water- and alcohol-soluble antioxidants in Valentina amaranth, mg.Eq.GK/g

\begin{tabular}{c|c|c|c|c}
\hline \multirow{2}{*}{ Sample } & \multicolumn{2}{|c|}{ Protected Ground } & \multicolumn{2}{c}{ Open Ground } \\
\cline { 2 - 4 } & Water & $\mathrm{C}_{2} \mathrm{H}_{5} \mathrm{OH}$ & Water & $\mathrm{C}_{2} \mathrm{H}_{5} \mathrm{OH}$ \\
\hline Leaves & $1.88 \pm 0.09$ & $0.65 \pm 0.03$ & $1.65 \pm 0.08$ & $0.63 \pm 0.03$ \\
\hline Stems & $0.80 \pm 0.04$ & $0.38 \pm 0.02$ & $0.90 \pm 0.05$ & $0.23 \pm 0.01$ \\
\hline Roots & $1.15 \pm 0.06$ & $0.30 \pm 0.02$ & $0.80 \pm 0.01$ & $0.19 \pm 0.01$
\end{tabular}

Moreover, a lower content of water- and alcohol-soluble antioxidants was found in stems of seedlings of both variants, but it was comparable with leaves.

Flavonoids have previously been shown to be contained in leaves of Valentina amaranth [19]. It should be noted that electrochemical oxidation of low molecular weight molecules with antioxidant activity of aqueous and alcoholic extracts can be described using flavonoids as an example by the following reaction: flavonoid $-\mathrm{O}-\mathrm{H}-$ flavonoid $-\mathrm{O}+\mathrm{e}+\mathrm{H}^{+}$.

Ability of ascorbic acid, amaranthine and flavonoid molecules to oxidize on electrode at a given potential indicates the ability of these molecules to capture free radicals [21]. The high total content of water and alcohol soluble antioxidants and ascorbic acid in the leaves of amaranth seedlings indicates a high antioxidant potential of seedlings, which actively protects young open ground plants from low temperature stress factors.

\section{Conclusions}

Low night temperature $\left(8 \ldots 10^{\circ} \mathrm{C}\right)$ in open ground has a positive effect on photosynthetic productivity, growth and development of seedlings. Moreover, their leaf mass is characterized by the maximum amount of ascorbic acid, a comparable amount of amaranthine and the total content of water- and alcohol-soluble antioxidants. At a lower night temperature, more ascorbic acid and hydrophilic antioxidants are accumulated in stems of open-ground plants compared to protected-seedlings grown at optimum temperature.

In the roots of seedlings grown in open ground, less ascorbic acid and a lower content of hydrophilic and hydrophobic antioxidants were found, which suggests a more active outflow of metabolites - antioxidants from roots to plant's aboveground organs.

The data obtained allows to recommend use of amaranth seedlings grown in open and protected ground as a dietary antioxidant product for preventive purposes.

\section{Введение}

В жарких и влажных регионах мира востребованными овощными культурами считаются листовые амаранты рода Amaranthus съедобных видов: A. tricolor, A. blitum, A. dubius, A. cruentus и A. Viridis [1-3]. Во многих странах Африки и Юго-Восточной Азии, в Индии и Южном Китае в пищу широко 
употребляют листовую зелень амаранта, выращивая ее как петрушку, листья и стебли которой применяют на пищевые цели. Молодые растения овощных видов амаранта используют при приготовлении разнообразных салатов, закусок, гарниров, супов, начинок для кондитерских изделий, напитков, макаронных изделий и даже народной медицине [4-7].

Столь широкое использование надземной части овощного амаранта в качестве пищевого продукта объясняется рядом причин, в т.ч. тем, что в этих странах практически не выращивают пряно-ароматические растения, а зелень во многих блюдах восполняет амарант [8,9]. Популярность овощных амарантов обусловлена их мягким пикантным вкусом и высокой питательной ценностью, их листья отличаются богатым содержанием безглютенового белка, витаминов, минералов, особенно кальция и железа, а также биологически активных веществ [10]. Кроме того, в целом ряде стран существует дефицит животного белка, а листья овощных видов амаранта содержат до 20 \% полноценного белка, сбалансированного по незаменимым аминокислотам. Поэтому население этих регионов пополняет недостаток пищевого белка путем сбора листьев дикорастущих овощных амарантов или выращивания сеянцев и приготовления на их основе разнообразных рационов [11].

В некоторых странах сеянцы (молодые растения) амаранта являются коммерческим товаром. В Индонезии овощной амарант выращивают на площади 2000 га. В тропических странах амарант высевают круглый год. Благодаря короткому циклу развития сеянцев (7-8 недель) их срезают на пищевое использование несколько раз за год.

Выращивание овощного амаранта в нечерноземной зоне на витаминную зелень сопряжено с рядом проблем. Например, возвратные холода в весенние месяцы апрель-май не позволяют провести сев семян амаранта в открытом грунте раньше конца мая или начала июня; дефицит влаги в засушливые годы может погубить урожай, поскольку сеянцы амаранта в большей степени нуждаются в поливе в отличие от взрослых растений. Помимо этого, всходы амаранта в открытом грунте могут страдать от сорной травы, скорость роста которой намного превосходит рост проростков амаранта, а позже молодые сеянцы могут уничтожить улитки [12]. При доращивании рассады амаранта в защищенном грунте таких проблем не возникает. Поэтому важно представлять закономерности изменения основных морфологических и биохимических показателей, определяющих продуктивность и питательную и фармакопейную ценность сеянцев, доращиваемых в открытом и защищенном грунте.

Цель работы - исследование морфологических и биохимических показателей сеянцев амаранта при доращивании их рассадным способом в открытом и защищенном грунте на пищевое использование.

\section{Материалы и методы}

Объектом исследования являются растения амаранта овощного вида Amaranthus tricolor L., сорта Валентина селекции ВНИИ селекции и семеноводства овощных культур (Московская область). Для посева семян использовали кассеты с предварительно увлажненной торфяной смесью. Посев проводили на глубину 0,5 ...1 см. После достижения 4-недельного возраста проростки пересаживали 
в почву в защищенном и открытом грунте [13]. Растения выращивали в открытом грунте на дерново-подзолистой почве с тяжелым механическим составом при ночной температуре $8 \ldots 14^{\circ} \mathrm{C}$ и дневной $9 \ldots 25^{\circ} \mathrm{C}$, а в защищенном грунте при ночной температуре $14 \ldots 17^{\circ} \mathrm{C}$ и $22 \ldots 30^{\circ} \mathrm{C}$ при дневной.

Молодые растения в возрасте 6-7 недель срезали и изучали морфометрические показатели: высоту растений, массу растений, листьев, стебля, корня, длину и ширину листовой пластинки. В опыте сравнивали растения амаранта сорта Валентина, выращенные в условиях защищенного и открытого грунта. С каждого опытного участка было собрано по 15 растений.

Биохимические исследования проводили в лаборатории физиологии и биохимии интродукции и функциональных продуктов ФГБНУ ФНЦО в 2018 г. В опытах использовали водные и спиртовые экстракты листьев, стеблей и корней сеянцев.

Экстракцию измельченных листьев и других органов растения проводили дистиллированной водой при комнатной температуре (гидромодуль 1:10) с последующим центрифугированием при 10000 об/мин. Количество амарантина в водных экстрактах определяли спектрофотометрическим методом с учетом молярного коэффициента экстинкции $5,66 \cdot 10^{4} \cdot \mathrm{M}^{-1} \cdot \mathrm{cm}^{-1}$ и молярного веса 726,6 [14]. Содержание восстановленной формы аскорбиновой кислоты (АК) определяли йодометрическим методом, основанным на титровании аскорбиновой кислоты в окрашенных экстрактах йодатом калия в кислой среде в присутствии йодистого калия и крахмала [15]. Суммарное содержание антиоксидантов определяли амперометрическим методом, результат выражали в эквивалентах галловой кислоты мг-экв. ГК/г. Измерения проводили на приборе «Цвет-Яуза 01-АА» в постоянном токовом режиме [16]. Измельчение образцов проводили в присутствии определенного объема экстрагирующей жидкости (бидистиллированная вода, $96 \%$ этиловый спирт) на гомогенизаторе при температуре $20 \ldots 25^{\circ} \mathrm{C}$. Далее гомогенизат центрифугируется при $10000 \mathrm{~g} 15$ мин при $4{ }^{\circ} \mathrm{C}$. Аликвоту супернатанта использовали для определения суммарного содержания антиоксидантов, при необходимости, разбавляя.

В табл. $1-4$ приведены средние арифметические значения величины и стандарты отклонения.

\section{Результаты и обсуждения}

Из темноокрашенных семян амаранта, A. tricolor сорта Валентина высеянных в кассеты, всходы появились с интервалом в двое суток. Наблюдали замедленный прирост высоты проростка в стадии развития первой пары настоящих листьев и резкое увеличение высоты растения с развитием последующих листьев. При получении хорошо развитых семядольных и первой пары настоящих листьев рассаду пересаживали в защищенный и открытый грунт.

Анализ морфометрических показателей растения перед срезкой выявил, что сеянцы амаранта, выращенные в защищенном грунте, отличались существенно более высокими морфометрическими показателями по сравнению с сеянцами, выращенными в открытом грунте.

Фотосинтетическая продуктивность надземной массы растений была существенно выше у сеянцев защищенного грунта. При выращивании растений амаранта 
в закрытом грунте на стадии сеянцев формируется более массивный главный побег (стебель) с меньшей массой листьев по сравнению с растениями открытого грунта. Изучение структуры урожая сеянцев показало, что надземная масса сеянцев, выращенных в открытом грунте, на 52 \% состоит из листьев, на $35 \%$ - из стеблей от общей массы растения, в то время как в защищенном грунте у молодых растений формируется листьев - 42 \% и стеблей 44 \% от общей массы растения (табл. 1).

Таблица 1

Определение структуры сеянцев амаранта сорта Валентина, выращенных в открытом и защищенном грунте

\begin{tabular}{c|c|c|c|c}
\hline \multirow{2}{*}{ Грунт } & $\begin{array}{c}\text { Macса растения, } \\
\Gamma\end{array}$ & $\begin{array}{c}\text { Масса листьев, г } \\
\text { Доля от массы } \\
\text { растения, \% }\end{array}$ & $\begin{array}{c}\text { Масса стеблей, г } \\
\text { Доля от массы } \\
\text { растения, \% }\end{array}$ & $\begin{array}{c}\text { Масса корней, г } \\
\text { Доля от массы } \\
\text { растения, \% }\end{array}$ \\
\hline Открытый & 2,52 & 1,30 & 0,90 & 0,32 \\
\hline Защищенный & 7,96 & $52 \%$ & $35 \%$ & $13 \%$ \\
\cline { 2 - 5 } & & 3,36 & 3,5 & 1,1 \\
\hline
\end{tabular}

Интересно отметить, что масса корней у сеянцев обоих вариантов составляла $13 \ldots 14$ \% от надземной массы. Это позволяет предположить, что фотосинтетические метаболиты в растениях открытого грунта накапливаются в большем количестве в листьях, тогда как в растениях защищенного грунта распределяются практически равномерно между листьями и стеблями.

Пищевую и фармакопейную ценность листьев амаранта A. tricolor L. сорта Валентина составляет не только безглютеновый белок, сбалансированный по незаменимым аминокислотам, но и биологически активные вещества с антиоксидантной активностью, которые воздействуют на физиологические функции организма человека, эффективно участвуя в метаболических и защитных реакциях [17]. Из эссенциальных нутриентов необходимым компонентом жизнедеятельности человека является аскорбиновая кислота. Из овощных культур болгарский перец накапливает аскорбиновую кислоту в высокой концентрации до 200 мг\%, а также листовые овощные растения: хризантема овощная до 80 мг\%, а водяной кресс и кориандр до 150 мг\% [18].

Таблица 2

Содержание аскорбиновой кислоты в органах растения амарант сорта Валентина, выращенных в условиях защищенного и открытого грунта

\begin{tabular}{c|c|c}
\hline \multirow{2}{*}{ Органы растения } & \multicolumn{2}{|c}{ Содержание аскорбиновой кислоты } \\
\cline { 2 - 3 } & Защищенный грунт & Открытый грунт \\
\hline Листья & 108 & 167 \\
\hline Стебли & 19,8 & 44 \\
\hline Корни & 25,12 & 22,8
\end{tabular}

Сеянцы амаранта аккумулируют восстановленную аскорбиновую кислоту во всех органах, однако в неодинаковом количестве. Данные, приведенные в табл. 2, указывают, что максимальное количество аскорбиновой кислоты накапливается в листьях обоих вариантов, а минимальное - в стеблях сеянцев защищенного грунта и в корнях сеянцев открытого грунта. Полученные данные указывают, что содержание аскорбиновой кислоты в различных органах растения зависит от температурных условий выращивания. Известно, что при низкой 
положительной температуре в растительной клетке образуются активные формы кислорода, из которых наибольшую опасность представляет супероксидный анион-радикал. Аскорбиновая кислота способна обезвреживать $\mathrm{O}_{2}^{2}$. В открытом грунте снижение ночной температуры до $8^{\circ} \mathrm{C}$ и ниже для теплолюбивых сеянцев является стресс-фактором, замедляющим их рост и развитие. В этих условиях защитой от действия супероксидных анион-радикалов служит аскорбиновая кислота, уровень которой в листьях амаранта, выращенного в открытом грунте, в 1,5 раза превышает таковой в листьях растений защищенного грунта. В стеблях сеянцев защищенного грунта аккумулируется меньше аскорбиновой кислоты по сравнению с листьями в 5,45 раза, а в стеблях сеянцев открытого грунта накапливается аскорбиновой кислоты в 3,7 раза меньше, чем в листьях. Неодинаковое количество аскорбиновой кислоты обнаружено в корнях молодых растений, выращенных в открытом и защищенном грунте. Аскорбиновая кислота накапливается в большем количестве в листьях и стеблях сеянцев, выращенных в открытом грунте, что может указывать на ее активную генерацию в условиях слабого низкотемпературного стресса. Помимо аскорбиновой кислоты в обезвреживании супероксидного аниона-радикала участвует красноокрашенный пигмент амарантин с антиоксидантной активностью, сравнимой с активностью супероксид дисмутазы [19]. Листья и соцветия сеянцев амарантов обоих вариантов выращивания содержат практически сравнимые количества амарантина, в то время как стебли молодых растений открытого грунта накапливают в 1,5 раза больше антиоксиданта, чем стебли сеянцев защищенного грунта.

Таблица 3

Определение амарантина в различных органах растений амаранта

A. tricolor L. сорта Валентина, мг на г сыр. массы

\begin{tabular}{c|c|c}
\hline Образец & В защищенном грунте & В открытом грунте \\
\hline Листья & $0,62 \pm 0,03$ & $0,59 \pm 0,03$ \\
\hline Стебли & $0,22 \pm 0,01$ & $0,34 \pm 0,02$
\end{tabular}

Изучение суммарного содержания антиоксидантов в листьях и стеблях сеянцев амаранта, выращенных в защищенном и открытом грунте, выявило максимальное содержание антиоксидантов в водных экстрактах, которое в 2,5 ...3 раза превышало уровень антиоксидантов, экстрагированных в спиртовом экстракте.

Таблица 4

Определение суммы водо- и спирторастворимых антиоксидантов в различных органах растений амарант A. tricolor L. сорта Валентина, выращенных в защищенном и открытом грунте, мг. экВ. ГК/г

\begin{tabular}{c|c|c|c|c}
\hline \multirow{2}{*}{ Образец } & \multicolumn{2}{|c|}{ В защищенном грунте } & \multicolumn{2}{c}{ В открытом грунте } \\
\cline { 2 - 5 } & Вода & $\mathrm{C}_{2} \mathrm{H}_{5} \mathrm{OH}$ & Вода & $\mathrm{C}_{2} \mathrm{H}_{5} \mathrm{OH}$ \\
\hline Листья & $1,88 \pm 0,09$ & $0,65 \pm 0,03$ & $1,65 \pm 0,08$ & $0,63 \pm 0,03$ \\
\hline Стебли & $0,80 \pm 0,04$ & $0,38 \pm 0,02$ & $0,90 \pm 0,05$ & $0,23 \pm 0,01$ \\
\hline Корни & $1,15 \pm 0,06$ & $0,30 \pm 0,02$ & $0,80 \pm 0,01$ & $0,19 \pm 0,01$
\end{tabular}

При этом меньшее содержание водо- и спирторастворимых антиоксидантов обнаружено в стеблях сеянцев обоих вариантов, но сравнимо с листьями.

Ранее мы показали, что в листьях амаранта сорта Валентина содержатся флавоноиды. Следует отменить, что электрохимическое окисление низкомолекулярных молекул с антиоксидантной активностью водных и спиртовых экстрактов 
может быть описано на примере флавоноидов следующей реакцией: флавоноид $-\mathrm{O}-\mathrm{H} \rightarrow$ флавоноид $-\mathrm{O}+\mathrm{e}+\mathrm{H}^{+}[20]$.

Способность молекул аскорбиновой кислоты, амарантина, флавоноидов окисляться на электроде при заданном потенциале свидетельствует о способности данных молекул улавливать свободные радикалы [21]. Высокое суммарное содержание водо- и спирторастворимых антиоксидантов и аскорбиновой кислоты в листьях сеянцев амаранта указывает на высокий антиоксидантный потенциал сеянцев, который активно защищает молодые растения открытого грунта от низкотемпературного стресс-фактора.

\section{Вывод}

Низкая ночная температура $\left(8 \ldots 10^{\circ} \mathrm{C}\right)$ в открытом грунте положительно сказывается на фотосинтетической продуктивности, росте и развитии сеянцев. При этом их листовая масса отличается максимальным количеством аскорбиновой кислоты, сравнимым количеством амарантина и суммарным содержанием водои спирторастворимых антиоксидантов. При пониженной ночной температуре в стеблях растений открытого грунта накапливается больше аскорбиновой кислоты и гидрофильных антиоксидантов по сравнению с сеянцами защищенного грунта, выращенными при оптимальной температуре.

В корнях сеянцев, выращенных в открытом грунте, обнаружено меньшее количество аскорбиновой кислоты и более низкое содержание гидрофильных и гидрофобных антиоксидантов, что позволяет предположить более активный отток метаболитов - антиоксидантов из корней в надземные органы растения.

Полученные данные позволяют рекомендовать использование сеянцев амаранта, выращенных в открытом и защищенном грунте, в качестве диетического антиоксидантного продукта профилактического назначения.

\section{References}

1. Rastogi A, Shukla S. Amaranth: A new millennium crop of nutraceutical values. Critical reviews in food science and nutrition. 2013; 53(2):109 - 125. doi: 10.1080/10408398.2010.517876

2. Bhattacharyya B, Johri BM. Amaranthaceae. In: Bhattacharyya B, Johri BM. (eds.) Flowering plants: Taxonomy and phylogeny. Delphi: Narosa Publishing House; 1998. p. 113.

3. Das S. Systematics and taxonomic delimitation of vegetable, grain and weed Amaranthus: a morphological and biochemical approach. Genet Resour Crop Evol. 2012; 59(2):289-303. doi: 10.1007/s10722-011-9684-7

4. Peter K, Gandhi P. Rediscovering the therapeutic potential of amaranthus species: A review. Egyptian Journal of Basic and applied Sciences. 2017; 4(3):196-205. Available from: doi: 10.1016/ j.ejbas. 2017.05.001

5. Rahmatullah M, Hosain M, Rahman S, Akter M. Antyhyperglycaemic and antinociceptive activity evaluation of methanolic extract of whole plant of Amaranthus tricolor L. (Amaranthaceae). Afr. J. Trad. Complement Altern Med. 2013; 10(5):408-411. doi: 10.4314/ajtcam.v10i5.31

6. Aneja S, Vats M, Aggarwal S, Sardana S. Phytochemistry and hepatoprotective activity of aqueous extract of Amaranthus tricolor Linn. roots. J. Ayurveda Integr. Med. 2013; 4(4):211-215. doi: 10.4103/0975-9476.123693

7. Clemente AC, Desai PV. Evaluation of the hematological, hypoglycemic, hypolipidemic and antioxidant properties of Amaranthus tricolor leaf extract in rat. Tropical Journal of Pharmaceutical Research. 2011; 10(5):595-602. doi: doi.org/10.4314/tjpr.v10i5.8 
8. Sarker U, Islam MT, Rabbani MG, Oba S. Variability, heritability and genetic association in vegetable amaranth (Amaranthus tricolor). Spanish Journal of Agricultural Research. 2015; 13(2):1-8. doi: 10.5424/sjar/2015132-6843

9. Sarker U, Islam MT, Rabbani MG, Oba S. Genotype variability in composition of antioxidant vitamins and minerals in vegetable amaranth. Genetika. 2015; 47(1):85-96. doi: 10.2298/GENSR1501085S

10. Robbins RJ. Phenolic acids in foods: an overview of analytical methodology. J. Agric Food Chem. 2003; 51(10):2866-2887. doi: 10.1021/jf026182t

11. Berberich S. History of amaranth. Agric. Res. 1980; 29(4):14.

12. Gins MS, Gins VK, Kononkov PF. Introduktsiya amaranta v Rossii [Amaranth introduction in Russia]. Moscow. 2019. (In Russ).

13. Gins MS, Gins VK, Kononkov PF, Pivovarov VF, Romanova EV, Osokin IE, Gins EM. Tekhnologiya vyrashchivaniya ovoshchnogo (listovogo) amaranta [Technology for growing vegetable (leaf) amaranth]. Moscow: RUDN Publ.; 2017. (In Russ).

14. Baiwas M, Dey S, Sen R. Betalains from Amaranthus tricolor L. Journal of Pharmacognosy and Phytochemistry. 2013; 1(5):87-95.

15. Sapozhnikova EV, Dorofeeva LS. Determination of ascorbic acid content in colored plant extracts by iodometric method. Food industry. 1966; (5):29-31. (In Russ).

16. Gins M.S., Gins V.K., Baykov A.A., Romanova E.V., Kononkov P.F., Torres M.K., Lapo O.A. Metodika analiza summarnogo soderzhaniya antioksidantov $v$ listovykh $i$ listostebel'nykh ovoshchnykh kul'turakh [Methodology for the analysis of the total content of antioxidants in leafy and leafy vegetable crops]. Moscow: RUDN Publ.; 2013. (In Russ).

17. Gins MS, Gins VK. Fiziko-biokhimicheskie osnovy introduktsii i selektsii ovoshchnykh kul'tur [Physico-biochemical fundamentals of the introduction and selection of vegetable crops]. Moscow: RUDN Publ.; 2011. (In Russ).

18. Sarker U, Oba S. Drought stress effects on growth, ROS markers, compatible solutes, phenolics, flavonoids, and antioxidant activity in Amaranthus tricolor. Appl Biochem Biotechnol. 2018; 186(4):999-1016. doi.org/10.1007/s12010-018-2784-5

19. Piattelli M. Betalains. In: Goodwin TW. (ed.) Chemistry and biochemystry of plant pigments. N.Y.: Acad. Press; 1976. p.560-596.

20. Blokhina O, Fagerstedt KV. Oxidative metabolism, ROS and NO under oxygen deprivation. Plant Physiology and Biochemistry. 2010; 48(5):359-373. doi.org/10.1016/j.plaphy.2010.01.007

21. Vladimirov YA, Proskurnina EV, Demin EM, Matveeva NS, Lyubitsky OB, Novikov AA. et al. Dihydroquercetin (taxifolin) and other flavonoids as inhibitors of the formation of free radicals at key stages of apoptosis. Biochemistry. 2009; 74(3):372-379.

\section{Библиографический список}

1. Rastogi A., Shukla S. Amaranthus: A new millennium crop of nutraceutical values // Critical reviews in food science and nutrition. 2013. Vol. 53. P. 109-125. doi:10.1080/ 10408398.2010.517876

2. Bhattacharyya B., Johri B.M. Amaranthaceae // Bhattacharyya B. Johri B.M (Eds.), Flowering plants: Taxonomy and phylogeny. Delphi : Narosa Publishing House, 1998. P. 113-113.

3. Das $S$. Systematic and taxonomic delimitation of vegetable, grain and weed Amaranthus: a morphological and biochemical approach // Genet Resour crop Evol. 2012. № 59. P. 289-303.

4. Kavita Peter, Puneet Gandhi. Rediscovering the therapeutic potential of amaranthus species: A review // Egyptian Journal of Basic and applied Sciences. 2017. http: dx.doi.org/10.1016/ j.ejbas.2017.05.001

5. Rahmatullah M., Hosain M., Rahman S. et all. Antyhyperglycaemic and antinociceptive activity evaluation of methanolic extract of whole plant of Amaranthus tricolor L. (Amaranthaceae) // Afr. J. Trad. Complement Altern Med. 2013. № 10. P. 408-411. 
6. Aneja S., Vats M., Aggarwal S., Sardana S. Phytochemistry and hepatoprotective activity of aqueous extract of Amaranthus tricolor Linn. Roots // J. Ayurveda Integr. Med. 2013. 4. P. 211-215.

7. Clemente A.C., Desai P.V. Evaluation of the hematological, hypoglycemic, hypolipidemic and antioxidant properties of Amaranthus tricolor leaf extract in Rat // Tropical Journal of Pharmaceutical Research. 2011. № 10. P. 595-602.

8. Sarker U., Islam M.T., Rabbani M.G., Oba S. Variability, heritability and genetic association in vegetable amaranth (Amaranthus tricolor) // Spanish Journal of Agricultural Research. 2015. Vol. 13. № 2. P. 1 -8. doi: 10.5424/sjar/2015132-6843

9. Sarker U., Islam M.T., Rabbani M.G., Oba S. Genotype variability in composition of antioxidant vitamins and minerals in vegetable amaranth // Genetika. 2015. Vol. 47. P. 1. P. 85-96. doi: 10.2298/GENSR1501085S

10. Robbins R.J. Phenolic acids in foods: an overview of analytical methodology // J. Agric Food Chem. 2003. Vol. 51. P. 2866-2887.

11. Berberich S. History of amaranth // Agric. Res. US. 1980. Vol. 29. № 4. P. 14.

12. Гинс М.С., Гинс В.К. Кононков П.Ф. Интродукция амаранта в России. М., 2019.

13. Гинс М.С., Гинс В.К., Кононков П.Ф., Пивоваров В.Ф., Романова Е.В., Осокин И.Е., Гинс E.M. Технология выращивания овощного (листового) амаранта. М., 2017.

14. Mousumi Baiwas, Satyahari Dey, Ramkrishna Sen. Betalains from Amaranthus tricolor L. // Journal of Pharmacognosy and Phytochemistry. 2013. Vol. 1 № 5. P. 87-95.

15. Сапожникова Е.В., Дорофеева Л.С. Определение содержания аскорбиновой кислоты в окрашенных растительных экстрактах йодометрическим методом // Консервная и овощесушильная промышленность. 1966. № 5. С. 29-31.

16. Гинс М.С., Гинс В.К., Байков А.А., Романова Е.В., Кононков П.Ф., Торрес М.К., Лапо О.А. Методика анализа суммарного содержания антиоксидантов в листовых и листостебельных овощных культурах. М., 2013.

17. Гинс М.С., Гинс В.К. Физико-биохимические основы интродукции и селекции овощных культур. М. : РУДН, 2011, 128 с.

18. Sarker U., Oba S. Drought stress effects on growth, ROS markers, compatible solutes, phenolics, flavonoids, and antioxidant activity in Amaranthus tricolor. Appl Biochem Biotechnol. 2018. Vol. 186. № 4. P. 999-1016. doi.org/10.1007/s12010-018-2784-5

19. Piattelli M. Betalains // Chemistry and bioche-mystry of plant pigments / Goodwin TW., ed. N.Y. : Acad. Press, 1976. P. 560-596.

20. Blokhina O., Fagerstedt K.V. Oxidative metabolism, ROS and NO under oxygen deprivation // Plant Physiology and Biochemistry. 2010. Vol. 48. № 5. P. 359-373. doi.org/10.1016/j.plaphy.2010.01.007

21. Владимиров Ю.А., Проскурина Е.В., Демин Е.М., Матвеева Н.С., Любиикий О.Б., Новиков А.А., Измайлов Д.Ю., Осипов А.Н., Тихонов В.П., Каган В.Е. Дигидрокверцетин (таксифолин) и другие флавоноиды как ингибиторы образования свободных радикалов на ключевых стадиях апоптоза // Биохимия. 2009. Т. 74. № 3. С. 372 -379.

\section{About authors:}

Sergiev Iskren Georgiev - Associate professor, PhD, Institute of Plant Physiology and Genetics, Bulgarian Academy of Sciences; 21 Acad. Georgi Bonchev St., Sofia, Bulgaria, 1113; ORCID ID: 0000-0002-2420-9146; Scopus ID: 6603230596; e-mail: iskren@bio21.bas.bg

Todorova Desislava Aleksandrova - Associate professor, PhD, Institute of Plant Physiology and Genetics, Bulgarian Academy of Sciences; 21 Acad. Georgi Bonchev St., Sofia, Bulgaria, 1113; ORCID ID: 0000-0001-7100-834X; Scopus ID: 55569034700; e-mail: dessita@ bio21.bas.bg

Gins Valentina Karlovna - Doctor of Biological Sciences, professor, chief researcher at Laboratory of Plant Physiology and Biochemistry and Introduction of Federal Scientific Vegetable Center; 14 Selektsionnaya st., VNIISSOK village, Moscow region, Odintsovo, Russian Federation, 143072; e-mail: anirr@bk.ru; ORCID ID: 0000-0002-7053-4345 
Motyleva Svetlana Mikhailovna - Candidate of Agricultural Science, Associate Professor, Head of Laboratory of Physiology and Biochemistry of All-Russian Horticultural Institute for Breeding, Agrotechnology and Nursery; 4 Zagoryevskaya st., Moscow, Russian Federation; ORCID ID: 00000003-3390-1958; SCOPUS ID: 55996650700

Gins Ekaterina Muratovna - Junior Researcher, Lorch Potato Research Institute; 23 Lorha st., Kraskovo village, Lyubertsy district, Moscow region, 140051, Russian Federation; ORCID ID: 0000-0002-5685-6305

Moskalev Evgeny Aleksandrovich - Junior Researcher, Lorch Potato Research Institute; 23 Lorha st., Kraskovo village, Lyubertsy district, Moscow region, 140051, Russian Federation; ORCID ID: 0000-0002-4904-1159

\section{Об авторах:}

Сергиев Искрен Георгиев - доцент, доктор наук, Институт физиологии и генетики растений, Болгарская академия наук, Болгария, 1113, София, ул. Георгия Бончева, корп. 21, e-mail: iskren@bio21.bas.bg, ORCID ID: 0000-0002-2420-9146 SCOPUS ID: 6603230596

Тодорова Десислава Александрова - доцент, доктор наук, руководитель (регуляторы роста и развития растений), Институт физиологии и генетики растений, Болгарская академия наук, Болгария, 1113, София, ул. Георгия Бончева, корп. 21, e-mail: dessita@bio21.bas.bg, ORCID ID: 0000-0001-7100-834X Scopus ID 55569034700

Гинс Валентина Карловна - доктор биологических наук, профессор, главный научный сотрудник лаборатории физиологии и биохимии растений и интродукции Федерального государственного бюджетного научного учреждения «Федеральный научный центр овощеводства», Российская Федерация, 143072, Московская обл., Одинцовский p-н, п. ВНИИССОК, ул. Селекционная, д. 14; e-mail: anirr@ bk.ru, ORCID ID: 0000-0002-7053-4345

Мотылева Светлана Михайловна - кандидат сельскохозяйственных наук, доцент, заведующий лаборатории физиологии и биохимии Федерального государственного бюджетного научного учреждения «Всероссийский селекционно-технологический институт садоводства и питомниководства», Российская Федерация, 115598, г. Москва, ул. Загорьевская, д. 4, ORCID ID:0000-0003-3390-1958 Scopus ID: 55996650700

Гинс Екатерина Муратовна - младший научный сотрудник Федерального государственного бюджетного научного учреждения «Всероссийский научно-исследовательский институт картофельного хозяйства имени А.Г. Лорха», Российская Федерация, 140051, Московская область, Люберецкий район, п. Красково, ул. Лорха, д. 23, литера «B» ORCID ID: 0000-00025685-6305

Москалев Евгений Александрович - младший научный сотрудник Федерального государственного бюджетного научного учреждения «Всероссийский научно-исследовательский институт картофельного хозяйства имени А.Г. Лорха», Российская Федерация, 140051, Московская область, Люберецкий район, п. Красково, ул. Лорха, д. 23, литера «B» ORCID ID: 00000002-4904-1159 